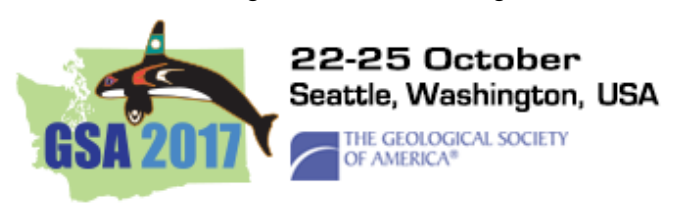

\title{
88-12: A NEW APPROACH FOR DEVELOPING CONTINUOUS AGE-DEPTH MODELS FROM DISPERSED CHRONOLOGIC DATA: APPLICATIONS TO THE MIOCENE SANTA CRUZ FORMATION, ARGENTINA
}

\author{
Sunday, 22 October 2017 \\ 09:00 AM - 05:30 PM \\ Washington State Convention Center - Halls 4EF
}

Traditional methods (linear regression, spline fitting) of age-depth modeling generate overly optimistic confidence intervals. Originally developed for ${ }^{14} \mathrm{C}$, Bayesian models (use of observations independent of chronology) allow the incorporation of prior information about superposition of dated horizons, stratigraphic position of undated points, and variations in sedimentology and sedimentation rate into model fitting. We modified the methodology of two Bayesian age depth models, Bchron (Haslett and Parnell, 2008) and OxCal (Ramsey, 2008) for use with U-Pb dates. Some practical implications of this approach include: a) model age uncertainties increase in intervals that lack closely spaced age constraints; $b$ ) models do not assume normal distributions, allowing for the non-symmetric uncertainties of sometimes complex crystal age probability functions in volcanic tuffs; c) superpositional constraints can objectively reject some cases of zircon inheritance and mitigate apparent age complexities. We use this model to produce an age-depth model with continuous and realistic uncertainties, for the early Miocene Santa Cruz Formation (SCF), Argentina. The SCF has produced a wide variety of fossil mammals and plant remains in an interval encompassing the end of the MMCO; placing these fossils in a temporal context is crucial for studies of changes to ecology and community structure though time.

New high precision isotope dilution U-Pb zircon dates for SCF tuffs yield weighted mean ages from $\sim 16.7$ to 17.6 Ma with an average uncertainty of $\pm 0.04 \mathrm{Ma}$. Our results are broadly similar to previously published ${ }^{40} \mathrm{Ar} /{ }^{39} \mathrm{Ar}$ plagioclase dates (Perkins et al, 2012), although one tuff differs by $\sim 0.4 \mathrm{Ma}$.

While age-depth model uncertainties near dated tuffs approach those for the dates themselves $( \pm 0.04 \mathrm{Ma})$, uncertainties approach $\pm 0.2 \mathrm{Ma}$ in poorly constrained parts of the section. Modeled sedimentation rates are high, $\sim 155 \mathrm{~m} \mathrm{Ma}^{-1}$, similar to previously reported rates (Perkins et al, 2012). We propagated age-depth model uncertainties to fossil stable isotope data collected from the SCF using a Monte Carlo technique. This approach allows us to estimate robust uncertainties on isotope composition through time, and compare terrestrial records of precipitation and temperature to high resolution marine proxies.

\section{Authors}

\section{Robin B. Trayler}

Boise State University

Mark D. Schmitz

Boise State University

Susana Bargo

Museo de La Plata

José I. Cuitiño

CENPAT-CONICET
Richard F. Kay.

Duke University

Matthew J. Kohn

Boise State University

Caroline A.E. Strömberg

University of Washington

Sergio F. Vizcaíno

Museo de La Plata 


\section{Final Paper Number 88-12}

View Related Events

Day: Sunday, 22 October 2017

Geological Society of America Abstracts with Programs. Vol. 49, No. 6, ISSN 0016-7592 doi: 10.1130/abs/2017AM-299206

(C) Copyright 2017 The Geological Society of America (GSA), all rights reserved. 